Jurnal Pendidikan Indonesia Gemilang, Vol 1, No.1, 2021, pp. 13-17

e-ISSN 27985091. DOI. 10.53889.jpig.v1i1.19

\title{
Upaya Meningkatkan Hasil Belajar IPA Siswa Kelas VII melalui Metode Mind Mapping
}

\author{
Disubmit 5 Agustus 2021, Direvisi 24 Agustus 2021, Diterima 30 Agustus 2021 \\ Ida Rufaida ${ }^{1}$ \\ ${ }^{1}$ SMP Negeri 1 Citeureup Kabupaten Bogor, Indonesia \\ Email Korespondensi: *idarufaida67@gmail.com
}

\begin{abstract}
Abstrak
Penelitian ini bertujuan untuk meningkatkan hasil belajar siswa pada mata pelajaran ilmu pengetahuan alam (IPA) melalui penerapan metode mind mapping. Penelitian dilaksanakan di salah satu SMP Negeri di Kabupaten Bogor, Indonesia. Penelitian ini merupakan penelitian tindakan kelas dengan menggunakan dua siklus. Hasil penelitian menunjukkan pada siklus 1 peserta didik yang sudah mencapai nilai KKM sebesar 59\% sedangkan pada tes akhir pembelajaran siklus 2 meningkat menjadi 82\%. Maka dapat disimpulkan bahwa metode mind mapping mampu meningkatkan hasil belajar peserta didik pada pelajaran IPA. Perlu diberikan pewarnaan pada mind mapping yang dibuat oleh agar pembelajaran menjadi lebih menarik jika akan dilakukan penelitian selanjutnya.
\end{abstract}

Kata Kunci: hasil belajar, IPA, mind mapping

\section{PENDAHULUAN}

Ilmu Pengetahuan Alam (IPA) adalah ilmu yang mempelajari hal-hal yang berkaitan dengan alam semesta baik isi maupun persitiwa yang terjadi di dalamnya (Nurdyansyah, 2018). Nurdyansyah (2018) menyatakan bahwa IPA terdiri atas fakta-fakta, konsep-konsep, maupun prinsip-prinsip yang berkaitan satu sama lain secara sistematis sehingga menjadi suatu proses untuk memproduksi pengetahuan. Dalam proses pembelajaran IPA ditemukan berbagai macam permasalahan salah satunya IPA merupakan pelajaran yang sulit dan menakutkan. Sehingga guru memegang peranan dalam mengendalikan suasana kelas agar dapat mencapai tujuan pembelajaran yang ditentukan oleh guru (Prasetyowati, 2014).

Hasil belajar siswa merupakan perubahan perilaku akibat belajar, perubahan perilaku ini terlihat dengan tercapainya penguasaan atas tujuan pembelajaran yang telah ditetapkan (Alwi, 2008; Hanafy, 2014). Berdasarkan pengertian tersebut, sangat penting untuk memperhatikan hasil belajar siswa dari sejak usia dini. Klasifikasi makhluk hidup merupakan salah satu konsep IPA yang ada pada level SMP. Klasifikasi makhluk hidup terdiri dari istilah klasifikasi dan makhluk hidup.

Pada penelitian ini, peneliti tertarik menggunakan mind mapping untuk konsep klasifikasi makhluk hidup untuk tingkat SMP. Mind mapping didefinisikan sebagai ekspresi berpikir yang berasal dari fungsi pikiran manusia berisi teknik grafis yang kuat dan kata kunci universal untuk membuka potensi otak (Buzan, 1993). Mind mapping fokus pada gambar, tema utama, cabang, dan kata kunci yang di hubungkan menggunakan garis (Ibrahim, 2013). Mind mapping atau peta pikiran mirip dengan peta konsep yang juga merupakan semacam 
organisator grafis, yang digambarkan sebagai representasi pengetahuan visual dua dimensi, termasuk diagram alur, garis waktu, dan tabel. Siswa dapat menunjukkan hubungan antar konsep atau proses melalui posisi spasial, garis penghubung dan gambar yang berpotongan (John dan Olusola, 2006). Berdasarkan hasil penelitian meta-analysis yang dilakukan oleh Liu et al (2014), metode mind mapping memberikan efek positif pada pengajaran dan pembelajaran di beberapa negara untuk penggunaan beberapa mata pelajaran. Selain itu, dapat juga mempengaruhi prestasi belajar siswa. Hal ini dikarenakan mind mapping merupakan salah satu metode pembelajaran yang popular menggunakan visualisasi untuk belajar.

Berdasarkan latar belakang tersebut, tujuan penelitian ini adalah untuk melihat peningkatan hasil belajar IPA siswa pada konsep klasifikasi makhluk hidup melalui metode mind mapping.

\section{METODE}

Penelitian tindakan kelas digunakan dalam penelitian ini dengan tahapan perencanaan, tindakan, pengamatan, refleksi, perencanaan ulang (Wibawa, 2003). Penelitian ini dilaksanakan di salah satu SMP negeri di Kabupaten Bogor, Indonesia selama enam bulan pada siswa kelas VII berjumlah 39 siswa. Prosedur kerja penelitian ini dirancang sebanyak 2 siklus yaitu siklus I dan siklus II.

\section{Rencana Tindakan}

Guru membuat rencana tindakan untuk siklus I dan siklus II, menyiapkan rencana pembelajaran, menentukan metode pembelajaran, menyusun alat penilaian, membuat lemabaran observasi untuk kolaborator.

\section{Pelaksanaan Tindakaan}

Meliputi beberapa fase kegiatan yang terdiri dari: Guru menyampaikan tujuan dan prosedur pembelajaran IPA melalui metode mind mapping, guru membimbing siswa belajar berkelompok, guru mengadakan Post Test, an guru menghimbau kepada siswa untuk mengenal IPA, supaya tidak beranggapan pelajaran IPA menakutkan.

\section{Observasi}

Memantau pelaksanaan pembelajaran IPA untuk menilai keaktifan guru dan keaktifan siswa.

\section{Refleksi}

Pada kegiatan refleksi dilakukan proses refleksi terhadap pembelajaran yang telah dilakukan. 


\section{HASIL DAN PEMBAHASAN}

Pada pembelajaran pra siklus, ditemukan bahwa aktivitas guru ternyata berpengaruh besar terhadap tercapainya tujuan pembelajaran. Dari data pengamatan aktivitas guru, guru belum memberikan hasil yang baik dalam hal penjelasan alur pelaksanaan pembelajaran. Sehingga peserta didik tampak masih banyak yang bingung harus melakukan apa dalam kelompok mereka. Peserta didik yang telah mencapai KKM adalah $43 \%$ dari target keberhasilan $75 \%$. Berdasarkan data nilai ulangan harian 1 dapat disimpulan bahwa hasil belajar peserta didik masih sangat rendah (Gambar 1).

Dengan demikian, dilakukanlah metode mind mapping kepada peserta didik pada pembelajaran di siklus I. Hasil yang didapat, siswa yang telah mencapai KKM adalah 59\%, dari target keberhasilan 75\%. Berdasarkan data nilai tes akhir pembelajaran dapat dinyatakan bahwa hasil belajar peserta didik masih rendah yang dapat dilihat pada Gambar 2.
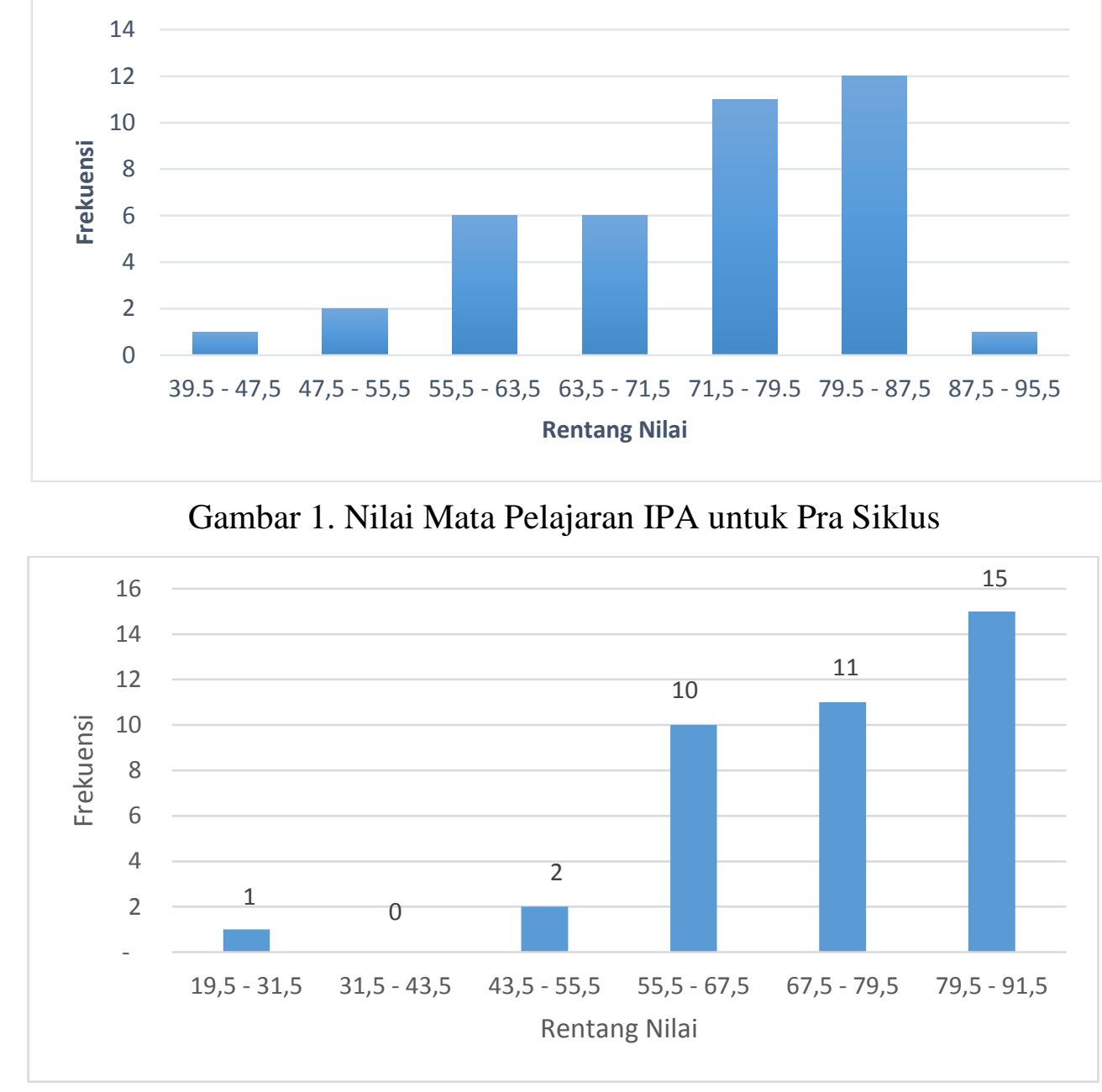

Gambar 2. Nilai Mata Pelajaran IPA untuk Siklus 1 
Dilakukan kembali metode pembelajaran mind mapping kepada peserta didik pada siklus II. Terdapat peningkatan persentase siswa yang berhasil mencapai KKM 75. Peserta didik yang telah mencapai KKM 75 adalah $82 \%$ dari target keberhasilan $75 \%$ yang dapat dilihat pada Gambar 3, hal ini berarti bahwa metode mind mapping dapat meningkatkan hasil belajar siswa pada konsep klasifikasi makhluk hidup. Menurut Chin \& Norhayati (2010), mind mapping digunakan secara luas di bidang pendidikan untuk brainstorming ide siswa, pelatihan dan pengembangan, serta mengorganisasikan ide dan pemecahan masalah. Lama penggunaan mind mapping juga memiliki faktor penting dalam keberhasilan peningkatan hasil belajar. Pada penelitian ini, mind mapping digunakan selama enam bulan. Liu et al (2014) menemukan bahwa penggunaan mind mapping selama 3-6 bulan adalah waktu yang paling efektif karena guru dapat memberikan arahan yang baik bagi siswa untuk belajar menggunakan mind mapping dalam waktu yang cukup.

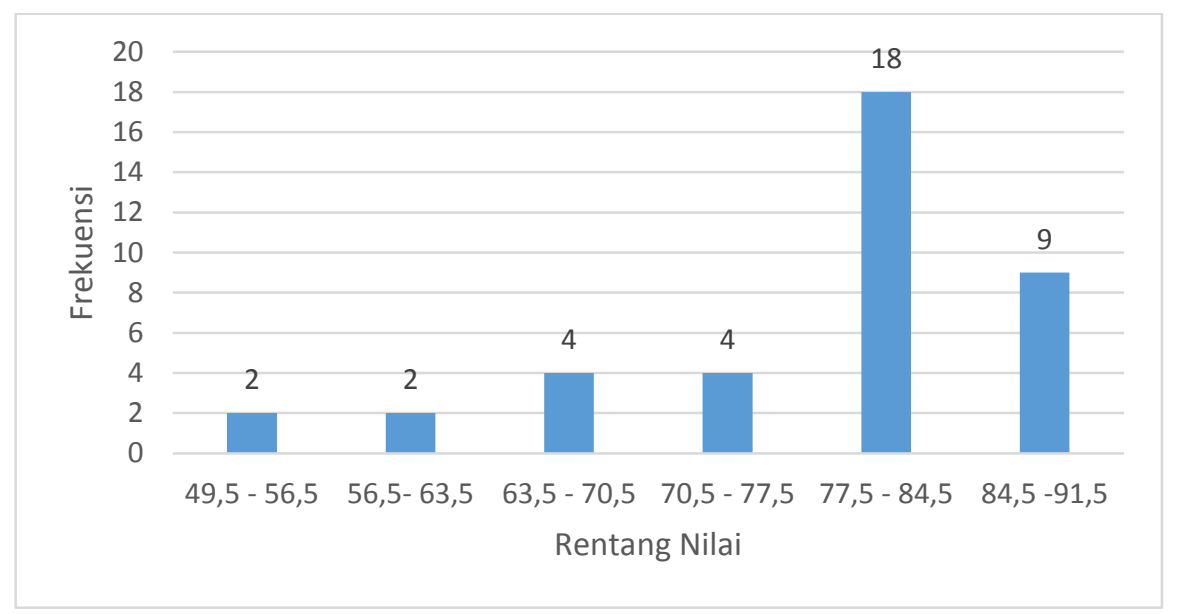

Gambar 3. Nilai Mata Pelajaran IPA untuk Siklus 2

\section{KESIMPULAN}

Berdasarkan hasil dari penelitian ini, dapat disimpulkan bahwa hasil belajar peserta didik menunjukkan peningkatan menggunakan metode mind mapping pada mata pelajaran IPA. Saran yang dapat diberikan untuk peneliti atau guru yang tertarik menggunakan metode mind mapping salah satunya adalah melakukan pewarnaan pada mind mapping yang sudah di buat oleh siswa agar menarik dipelajari.

\section{DAFTAR PUSTAKA}

Alwi, H. (2008). Kamus Umum Bahasa Indonesia. Jakarta : Balai Pustaka.

Buzan T, Buzan B. (1993). The mind map book: How to use radiant thinking to maximize your brain's untapped potential [J]. New York, Penguin Group 
Chin, SF, Norhayati M. (2010).Teacher-Centered Mind mapping vs Student-Centered Mind mapping in the Teaching of Accounting at Pre-U Level -An Action Research.Procedia Social and Behavioral Sciences.

Hanafy. (2014). Konsep Belajar dan Pembelajaran. Lentera Pendidikan. 17, No. 1.

Ibrahim, MAJ. (2013). The Impact of Digital Mind Maps on Science Achievement among Sixth Grade Students in Saudi Arabia[J]. Procedia - Social and Behavioral Sciences. 103: 1078-1087

John, CN, and Olusola, OA. (2006). Learning With Concept and Knowledge Maps: A MetaAnalysis. Review of Educational Research.76(3): 413-448

Liu, Y., Zhao, G., Ma, G., \& Bo, Y. (2014). The effect of mind mapping on teaching and learning: A meta-analysis. Standard Journal of Education and Essay, 2(1): 17-31.

Prasetyowati, R. (2014). Pembelajaran IPA SMP Menurut Kurikulum 2013. Makalah PPM, 18.

Wibawa, B. (2003). Penelitian Tindakan Kelas. Jakarta: Dirjen Dikdasmen. 